Dückers, M.L.A., Olff, M. Does the vulnerability paradox in PTSD apply to women and men? Ap exploratory study. Journal of Traumatic Stress: 2017, 30(2), 200-204

\begin{tabular}{|l|l|}
\hline $\begin{array}{l}\text { Postprint } \\
\text { Version }\end{array}$ & 1.0 \\
\hline Journal website & http://dx.doi.org/10.1002/its.22173 \\
\hline Pubmed link & $\underline{\text { https://www.ncbi.nlm.nih.gov/pubmed/28329423 }}$ \\
\hline DOI & $10.1002 /$ jts.22173 \\
\hline
\end{tabular}

This is a NIVEL certified Post Print, more info at http://www.nivel.eu

\title{
Does the Vulnerability Paradox in PTSD Apply to Women and Men? An Exploratory Study
}

\author{
MICHEL L.A. DÜCKERS ${ }^{1,2,3}$, MIRANDA OLFF ${ }^{3,4}$ \\ ${ }^{1}$ NIVEL-Netherlands Institute for Health Services Research, Utrecht, The Netherlands \\ ${ }^{2}$ Impact-National Knowledge and Advice Centre for Psychosocial Care Concerning Critical \\ Incidents, Diemen, The Netherlands \\ ${ }^{3}$ Arq Psychotrauma Expert Group, Diemen, The Netherlands \\ ${ }^{4}$ Department of Psychiatry, Academic Medical Centre, University of Amsterdam, Amsterdam, \\ The Netherlands
}

\begin{abstract}
Recent research suggests that greater country vulnerability is associated with a decreased, rather than increased, risk of mental health problems. Because societal parameters may have gender-specific implications, our objective was to explore whether the "vulnerability paradox" equally applies to women and men. Lifetime posttraumatic stress disorder (PTSD) prevalence data for women and men were retrieved from 11 population studies $(N=57,031)$ : conducted in Australia, Brazil, Canada, France, Lebanon, Mexico, Netherlands, Portugal, Sweden, Switzerland, and the United States. We tested statistical models with vulnerability, gender, and their interaction as predictors. The average lifetime PTSD prevalence in women was at least twice as high as it was in men and the vulnerability paradox existed in the prevalence data for women and men $\left(R^{2}=\right.$ .70). We could not confirm the possibility that gender effects are modified by socioeconomic and cultural country characteristics. Issues of methodology, language, and cultural validity complicate international comparisons. Nevertheless, this international sample points at a parallel paradox: The vulnerability paradox was confirmed for both women and men. The absence of a significant interaction between gender and country vulnerability implies that possible explanations for the paradox at the country-level do not necessarily require gender-driven distinction.
\end{abstract}

The lifetime risk for posttraumatic stress disorder (PTSD) in women is at least twice as high as the risk in men, a gender disparity that has received attention in several studies (Christiansen \& Hansen, 2015; Ditlevsen \& Elklit, 2010; Olff, Langeland, Draaijer, \& Gersons, 2007; Tolin \& Foa, 2006). Research suggests that greater exposure to trauma cannot account for the increased risk of PTSD in women 
(Yehuda et al., 2015). Although men might experience higher levels of exposure in general (often war-related exposure types), it is the type of trauma (such as sexual violence) to which women are more exposed rather than the level of exposure that has been associated with a higher conditional prevalence of PTSD in women. Many other psychological, social, and biological factors can potentially explain the greater vulnerability to PTSD in women compared to men (Olff et al., 2007).

To date, research has primarily focused on individual or group-level risk and protective factors against PTSD (Brewin, Andrews, \& Valentin, 2000; Ozer, Best, Lipsey, \& Weiss, 2003). Only a few empirical studies have examined the relevance of country-level factors. Recently, we identified a "vulnerability paradox"-a counterintuitive association between mental health and the resources of countries, measured using a broad collection of socioeconomic datasets (Dückers, Alisic, \& Brewin, 2016). We predicted the lifetime prevalence of PTSD in different countries using data from the World Risk Report, capturing various countries' overall cultural and socioeconomic vulnerability to adversity in one index (Welle \& Birkmann, 2016). Although at an individual person's level the possession of greater resources is protective against PTSD, we found that countries with greater wealth and equality, better health care and education, and longer life expectancy are characterized by a higher lifetime prevalence of PTSD (Brewin et al., 2000; Dückers et al., 2016). An additional study confirmed that higher exposure and lower vulnerability levels are accompanied by a higher prevalence in any mental disorder, with the largest effect size in mood disorders (Dückers \& Brewin, 2016). There are few explanations for this so far, but we can hypothesize that exposure has a relatively greater impact in a safe, well-resourced, well-organized environment, where people are more individualistic, less hindered by stigma and taboos, have high expectations about their prospects in life, and find it difficult to deal with the consequences of unanticipated obstacles in long-term goal realization (Dückers \& Brewin, 2016; Dückers et al., 2016).

In this study, we took gender differences in PTSD into account and sought to answer the following question: Does the vulnerability paradox apply to women and men? We hypothesized that it would. However, if we consider that some of the societal parameters may have gender-specific implications (e.g., access to the protective factor social support that women are known to be more likely to seek out) and may not be as commonplace in less-vulnerable, individualistic countries, the effect in women might be stronger than in men (Dückers et al., 2016; Olff, 2012; Olff et al., 2007). Vulnerability would in that case modify the effect of being female on PTSD prevalence.

\section{METHOD}

\section{Data Sources and Measures}

We retrieved lifetime PTSD prevalence data for both women and men from 11 population studies $(N=57,031)$ : Australia (Chapman et al., 2012), Brazil (Viana \& Andrade, 2012), Canada (Van Ameringen, Mancini, Patterson, \& Boyle, 2008), France (Husky, 2014; Husky, Lépine, Gasquet, \& Kovess-Masfety, 2015), Lebanon (Karam et al., 2008), Mexico (Borges, Benjet, Petukhova, \& Medina-Mora, 2014), The Netherlands (De Vries \& Olff, 2009), Portugal (De Albuquercue, Soares, Martins De Jesus, \& Alves, 2003), Sweden (Frans, Rimmö, Åberg, \& Fredrikson, 2005), Switzerland (Perrin et al., 2014), and the United States (Kessler et al., 2005). 
Dückers, M.L.A., Olff, M. Does the vulnerability paradox in PTSD apply to women and men? Anexploratory study. Journal of Traumatic Stress: 2017, 30(2), 200-204

In all of the studies, PTSD was assessed in representative samples according to the Diagnostic and Statistical Manual of Mental Disorders (4th ed., text rev.; American Psychiatric Association, 2000) criteria. In the case of Switzerland, a random sample was taken from an urban area $(N=3,691$; Perrin et al., 2014). Most of the population studies were based on the Clinical International Diagnostic Interview (CIDI; for example, see Kessler \& Üstün, 2008). The population studies in Switzerland, Sweden, and Portugal applied the Diagnostic Interview for Genetic Studies with the Schedule for Affective Disorders and Schizophrenia-lifetime and anxiety disorder version (SADS-LA), the PTSD Checklist (PCL), and the Short Screening Scale (SSC), respectively (De Albuquercue et al., 2003; Frans et al., 2005; Perrin et al., 2014).

Vulnerability data for the 11 countries were taken from the World Risk Report of 2016 (Welle \& Birkmann, 2016). In this report, the vulnerability of 171 countries was summarized using 23 indicators, divided into three categories (susceptibility, lack of coping capacity, and lack of adaptive capacities), and measured using worldwide and publicly accessible data. "Susceptibility" describes a country's structural characteristics and conditions that can sustain harm. For example, indicators of susceptibility involve malnutrition, access to sanitation, income equality, and gross domestic product per capita. "Lack of coping capacity" refers to the inability of a country to minimize negative impacts of events and includes indicators such as the number of physicians and hospital beds per 10,000 inhabitants and the level of public sector corruption. "Lack of adaptive capacities" refers to conditions that fail to support long-term, structural change. Example indicators include the adult literacy rate, combined gross school enrollment, forest management, and public and private health expenditure. Country vulnerability scores are calculated on a scale, ranging theoretically from 0 (minimum) to 100 (maximum), and can be interpreted as percentage values. More background information on the vulnerability index, its composition, and analysis can be found in the World Risk Report (Welle \& Birkmann, 2016).

The current analysis was conducted in three steps in IBM SPSS, version 20. In the first model we tested whether lifetime PTSD in women is higher than in men. In the next step country vulnerability was added to determine the presence of the paradox. The third model also included the interaction between gender and vulnerability.

\section{RESULTS}

Distributional information for the variables and the correlations between them are shown in Table 1. The average lifetime PTSD prevalence in men is 3.2\% $(n=11)$ and in women $7.8 \%(n=11)$. Vulnerability correlated strongly with lifetime PTSD prevalence in women $\left(r=-.60, R^{2}=.36, p=.051\right)$ and men $\left(r=-.79, R^{2}=.63, p=\right.$ .004).

[table 1]

In the first linear regression model (Table 2), female gender increases the chances of developing PTSD $(p<.001)$. In the second model this gender effect is maintained ( $p$ $<.001)$ after adding country vulnerability $(p=.002)$. The explained variance increases from $49.3 \%$ to $69.8 \%$. The interaction term in the third model does not significantly explain additional variance. The vulnerability paradox exists in the prevalence data for women and in the prevalence data for men (see Figure 1). The slope in the data for women seems a bit steeper; however, we could not statistically 
Dückers, M.L.A., Olff, M. Does the vulnerability paradox in PTSD apply to women and men? An exploratory study. Journal of Traumatic Stress: 2017, 30(2), 200-204

confirm the possibility that gender effects are modified by socioeconomic and cultural country characteristics. Figure 1 shows that the variation in estimated PTSD in women is higher than in men, which is reflected in a lower percentage of explained variance (although the effect size is large in both gender groups: $r \geq .50$; Rosenthal, 1996).

\section{[TABLE 2] [FIGURE 1]}

\section{DISCUSSION}

This international country sample points at a parallel paradox: The vulnerability paradox was confirmed for women and men. A higher level of country vulnerability appears to be accompanied by lower levels of PTSD and vice versa in both gender groups. The absence of a significant interaction between gender and country vulnerability implies that possible explanations for the paradox at country level do not necessarily require gender-driven distinction.

At the same time, the comparison of prevalence data is complicated and requires caution. It is important to recognize the potential problems in working with country datasets. Issues of methodology, language, and cultural validity complicate international comparisons (Dückers et al., 2016). We are aware of the possibility that national variation in mental health prevalence is affected by measurement error, country differences in stigma, and potential gender differences therein. Moreover, another issue to consider is that the vulnerability index, with its composition of social and economic datasets, also contains gender-sensitive country characteristics, particularly in the "gender parity" components clustered in lack of adaptive capacities (gender parity in education and share of female representatives in the National Parliament), and probably in components such as life expectancy at birth and purchasing power parity.

Unfortunately, we were unable to analyze the original population datasets and worked with aggregated prevalence data that can be influenced by regional variation and oversampling of risk-factor subgroups within populations (although measures were taken in the original studies to enhance representativeness). Despite the fact that the combined material is based on thousands of respondents, the national-level sample size was reduced to women and men in 11 countries: 22 PTSD estimates based on different sample sizes (the minimum sample consisted of 1,087 respondents). Furthermore, the studies on Portugal, Sweden, and Switzerland used an alternative diagnostic instrument. Excluding these three countries from the analysis did not change the results. All the estimated effects in the first two models (Table 2) remained significant $(n=16 ; p<.010)$. When only the Swiss urban sample was removed the results are unaffected as well $(n=20 ; p<.010)$.

What mostly hinders a broader assessment and replication of the vulnerability paradox is the lack of recent, representative, and comparable health population studies, in particular the absence of studies carried out in more vulnerable countries and considering factors such as the degree and nature of exposure. The findings from an earlier study, where exposure to trauma explained one third of the variance in PTSD as a single predictor, over half of the variance in combination with country vulnerability, and approximately three quarters when moderated by vulnerability, imply, for instance, that it is better to include both exposure and vulnerability as predictors because as single predictors they tend to underestimate lifetime PTSD in 
Dückers, M.L.A., Olff, M. Does the vulnerability paradox in PTSD apply to women and men? An exploratory study. Journal of Traumatic Stress: 2017, 30(2), 200-204

"high exposure-low vulnerability" populations (Dückers et al., 2016). In the current analysis exposure was not included and the robustness of the pattern indeed seems somewhat negatively affected by Switzerland: a low vulnerability country with a low-exposure level (Perrin et al., 2014), plausibly explained by not having been actively involved in warfare for 150 years and not having been confronted with major natural disasters in several decades (Hepp et al., 2005). Adding information on exposure to trauma among women and men is likely to improve the type of analysis presented here.

Besides these and other limitations, an important strength is that the vulnerability index has proven to be robust so far. The stability of the index is important given the gap between the years of data collection for trauma prevalence and the vulnerability construct. Changes over time in country vulnerability might affect its relationship with the prevalence of lifetime PTSD. The authors of the original vulnerability paradox article report that the correlation between the vulnerability scores in the 2012 and 2013 World Risk Report is almost perfect ( $r=.998, N=173$; Dückers et al., 2016). We checked the World Risk Report of 2015 (Welle \& Birkmann, 2015) and the vulnerability data used in this study, extracted from the 2016 report (Welle \& Birkmann, 2016), and found a similar correlation $(r=.991 ; N=11)$, suggesting that the vulnerability index is stable.

With these limitations and strengths in mind, the main conclusion emerging from the present exploratory study is that a higher level of country vulnerability seems to be accompanied by lower levels of PTSD and vice versa in women as well as in men. It is a challenging finding that needs to be further explored, as it may help us to better understand the role of gender in the multilayered mechanisms of resilience and vulnerability in the context of trauma.

\section{REFERENCIE}

American Psychiatric Association. (2000). Diagnostic and statistical manual of mental disorders (4th ed., text rev.). Washington, DC: Author.

Borges, G., Benjet, C., Petukhova, M., \& Medina-Mora, M. E. (2014). Posttraumatic stress disorder in a nationally representative Mexican community sample. Journal of Traumatic Stress, 27, 323-330. doi:10.1002/jts.21917

Brewin, C. R., Andrews, B., \& Valentine, J. D. (2000). Meta-analysis of risk factors for posttraumatic stress disorder in trauma-exposed adults. Journal of Consulting and Clinical Psychology, 68, 748-766. doi:10.1037/0022-006X.68.5.748

Chapman, C., Mills, K., Slade, T., McFarlane, A. C., Bryant, R. A., Creamer, M., ... Teesson, M. (2012). Remission from post-traumatic stress disorder in the general population. Psychological Medicine, 42, 1695-1703. doi:10.1017/S0033291711002856

Christiansen, D., \& Hansen, M. (2015). Accounting for sex differences in PTSD: A multivariable mediation model. European Journal of Psychotraumatology, 6, 26068. doi:10.3402/ejpt.v6.26068

De Albuquercue, A., Soares, C., Martins De Jesus, P., \& Alves, C. (2003). The epidemiology of PTSD in the adult population in Portugal. Acta Médica Portuguesa, 16, 309-320.

De Vries, G. J., \& Olff, M. (2009). The lifetime prevalence of traumatic events and posttraumatic stress disorder in the Netherlands. Journal of Traumatic Stress, 22, 259267. doi:10.1002/jts.20429

Ditlevsen, D. N., \& Elklit, A. (2010). The combined effect of gender and age on posttraumatic stress disorder: Do men and women show differences in the lifespan distribution of the disorder? Annals of General Psychiatry, 9, 32. doi:10.1186/1744-859X-9-32 
Dückers, M.L.A., Olff, M. Does the vulnerability paradox in PTSD apply to women and men? Anexploratory study. Journal of Traumatic Stress: 2017, 30(2), 200-204

Dückers, M. L. A., Alisic, E., \& Brewin, C. R. (2016). A vulnerability paradox in the crossnational prevalence of post-traumatic stress disorder. British Journal of Psychiatry, 209, 300-305. doi:10.1192/bjp.bp.115.176628

Dückers, M. L. A., \& Brewin, C. R. (2016). A paradox in individual versus national mental health vulnerability: Are higher resource levels associated with higher disorder prevalence? Journal of Traumatic Stress, 29, 572-576. doi:10.1002/jts.22144

Frans, Ö., Rimmö, P-A., Åberg, L., \& Fredrikson, M. (2005). Trauma exposure and posttraumatic stress disorder in the general population. Acta Psychiatrica Scandinavica, 111, 291-299. doi:10.1111/j.1600-0447.2004.00463.x

Hepp, U., Gamma, A., Milos, G., Eich, D., Ajdacic-Gross, V., Rössler, W., ... Schnyder, U. (2006). Prevalence of exposure to potentially traumatic events and PTSD. European Archives of Psychiatry and Clinical Neuroscience, 256, 151-158. doi:10.1007/s00406-0050621-7

Husky, M. (2014). Development of risk factors for suicides. European Journal of Public Health, 24, 262-263. doi:10.1093/eurpub/cku165.048

Husky, M., Lépine, J-P., Gasquet, I., \& Kovess-Masfety, V. (2015). Exposure to traumatic events and posttraumatic stress disorder in France: Results from the WMH survey. Journal of Traumatic Stress, 28, 275-282. doi:10.1002/jts.22020

Karam, Ã. I. G., Mneimneh, Z. N., Dimassi, H., Fayyad, J. A., Karam, A. N., Nasser, S. C., ... Kessler, R. C. (2008). Lifetime prevalence of mental disorders in Lebanon: First onset, treatment, and exposure to war. PLoS Medicine, 5, e61. doi:10.1371/journal.pmed.0050061

Kessler, R. C., Berglund, P. A., Demler, O., Jin, R., Merikangas, K. R., \& Walters, E. E. (2005). Lifetime prevalence and age-of-onset distributions of DSM-IV disorders in the National Comorbidity Survey Replication. Archives of General Psychiatry, 62, 593-602. doi:10.1001/archpsyc.62.6.593

Kessler, R. C., \& Üstün, T. B. (Eds.). (2008). The WHO World Mental Health Surveys: Global perspectives on the epidemiology of mental disorders. New York, NY: Cambridge University Press.

Olff, M. (2012). Bonding after trauma: On the role of social support and the oxytocin system in traumatic stress. European Journal of Psychotraumatology, 3, 18597.doi:10.3402/ejpt.v3i0.18597

Olff, M., Langeland, W., Draijer, N., \& Gersons, B. P. R. (2007). Gender differences in posttraumatic stress disorder. Psychological Bulletin, 133, 183-204. doi:10.1037/00332909.133.2.183

Ozer, E. J., Best, S. R., Lipsey, T. L., \& Weiss, D. S. (2003). Predictors of posttraumatic stress disorder and symptoms in adults: A meta-analysis. Psychological Bulletin, 129, $52-$ 73. doi:10.1037/0033-2909.129.1.52

Perrin, M., Vandeleur, C. L., Castelao, E., Rothen, S., Glaus, J., Vollenweider, P., \& Preisig, M. (2014). Determinants of the development of post-traumatic stress disorder, in the general population. Social Psychiatry and Psychiatric Epidemiology, 49, 447-457. doi:10.1007/s00127-013-0762-3

Rosenthal, J. A. (1996). Qualitative descriptors of strength of association and effect size. Journal of Social Services Research, 9, 37-59. doi:10.1300/J079v21n04_02

Tolin, D. F., \& Foa, E. B. (2006). Sex differences in trauma and posttraumatic stress disorder: A quantitative review of 25 years of research. Psychological Bulletin, 132, 959992. doi:10.1037/0033-2909.132.6.959

Van Ameringen, M., Mancini, C., Patterson, B., \& Boyle, M. H. (2008). Post-traumatic stress disorder in Canada. CNS Neuroscience \& Therapeutics, 14, 171-181. doi:10.1111/j.17555949.2008.00049.x

Viana, M. C., \& Andrade, L. H. (2012). Lifetime prevalence, age and gender distribution and age-of-onset of psychiatric disorders in the São Paulo metropolitan area, Brazil: Results from the São Paulo megacity mental health survey. Revista Brasileira de Psiquiatria, 34, 249-260. doi:10.1016/j.rbp.2012.03.001

Welle, T., \& Birkmann, J. (2015). The World Risk Index 2015. In World Risk Report 2015 (pp. 40-49). Berlin, Germany: Alliance Development Works.

Welle, T., \& Birkmann, J. (2016). The World Risk Index 2016. In World Risk Report 2016 (pp. 42-51). Berlin, Germany: Alliance Development Works. 
Dückers, M.L.A., Olff, M. Does the vulnerability paradox in PTSD apply to women and men? An exploratory study. Journal of Traumatic Stress: 2017, 30(2), 200-204

Yehuda, R., Hoge, C. W, McFarlane, A. C., Vermetten, E., Lanius, R. A., Nievergelt, C. M.,

... Hyman, S. E. (2015). Post-traumatic stress disorder. Nature Reviews Disease Primers,

1, 15057.doi:10.1038/nrdp.2015.57

\section{TABLES AND FIGURES}

Table 1. Distributional Information and Correlations

\begin{tabular}{|c|c|c|c|c|c|c|c|}
\hline \multirow[b]{2}{*}{ Variable } & \multicolumn{5}{|c|}{ Distributional information } & \multicolumn{2}{|c|}{ Correlations } \\
\hline & $N$ & $M$ & Min & Max & IQR & $\begin{array}{l}\text { PTSD in } \\
\text { women }\end{array}$ & $\begin{array}{c}\begin{array}{c}\text { PTSD in } \\
\text { men }\end{array} \\
\end{array}$ \\
\hline \multicolumn{8}{|c|}{$\begin{array}{l}\text { 1. Note. } \mathrm{PTSD}=\text { posttraumatic stress disorder; } N=\text { number of countries; } \mathrm{Min}= \\
\text { minimum value; } \mathrm{Max}=\text { maximum value; } \mathrm{IQR}=\text { interquartile range. } \\
\text { 2. } * p<.05 . * * p<.01 . * * * p<.001 .\end{array}$} \\
\hline $\begin{array}{l}\text { Lifetime PTSD prevalence } \\
\text { in women }(\%)\end{array}$ & 11 & 7.80 & 2.30 & 12.80 & 3.90 & 1 & \\
\hline $\begin{array}{l}\text { Lifetime PTSD prevalence } \\
\text { in men }(\%)\end{array}$ & 11 & $\mid 3.21$ & 0.50 & 5.30 & 3.10 & $.93 * * *$ & $\| 1$ \\
\hline $\begin{array}{l}\text { Vulnerability score }(0- \\
100)\end{array}$ & 11 & $\mid 32.48$ & 26.94 & 44.99 & 15.98 & -.60 & $\mid-.79 * *$ \\
\hline
\end{tabular}

Table 2. Summary of Regression Analysis for Variables Predicting Lifetime PTSD

\begin{tabular}{|c|c|c|c|c|c|c|c|c|c|}
\hline \multirow{2}{*}{ Variable } & \multicolumn{3}{|c|}{ Model 1} & \multicolumn{3}{|c|}{ Model 2} & \multicolumn{3}{|c|}{ Model 3} \\
\hline & $B$ & $S E$ & $\beta$ & $B$ & $S E$ & $\beta$ & $B$ & $S E$ & $\beta$ \\
\hline \multicolumn{10}{|c|}{$\begin{array}{l}\text { 1. Note. PTSD = posttraumatic stress disorder; } \mathrm{SE}=\text { standard error. The } \\
\text { predicted PTSD prevalence in women and men in } 11 \text { countries }(N=22) \text { is } \\
\text { based on Model 1: gender; Model } 2: \text { gender and vulnerability; Model 3: } \\
\text { gender moderated by vulnerability. } \\
\text { 2. }{ }^{\text {a }} \text { Dummy-coded variable (women compared to men). Women were assigned } \\
\text { the value of } 1 \text { and men the value } 0 \text {. } \\
\text { 3. }{ }^{*} p<.05 . * * p<.01 . * * * p<.001 \text {. }\end{array}$} \\
\hline Constant & $3.21 * * *$ & 0.74 & - & $9.99 * * *$ & 1.97 & - & $8.76 * *$ & 2.77 & D \\
\hline Gendera & $4.59 * * *$ & 1.04 & 0.70 & $4.59 * * *$ & 0.82 & 0.70 & 7.05 & 3.92 & 1.08 \\
\hline Vulnerability & & & & $-0.21 * *$ & 0.06 & -0.45 & -0.17 & 0.08 & -0.37 \\
\hline \begin{tabular}{|l} 
Gender $\times$ \\
Vulnerability
\end{tabular} & & & & & & & $\mid-0.08$ & 0.12 & -0.39 \\
\hline $\begin{array}{l}R^{2}(F \text { for change } \\
\left.\text { in } R^{2}\right)\end{array}$ & $49.3 \%$ & $9.45^{*}$ & & $69.8 \%$ & $2.92 *$ & & $70.5 \%$ & $0.41)$ & \\
\hline
\end{tabular}


Dückers, M.L.A., Olff, M. Does the vulnerability paradox in PTSD apply to women and men? Ap exploratory study. Journal of Traumatic Stress: 2017, 30(2), 200-204
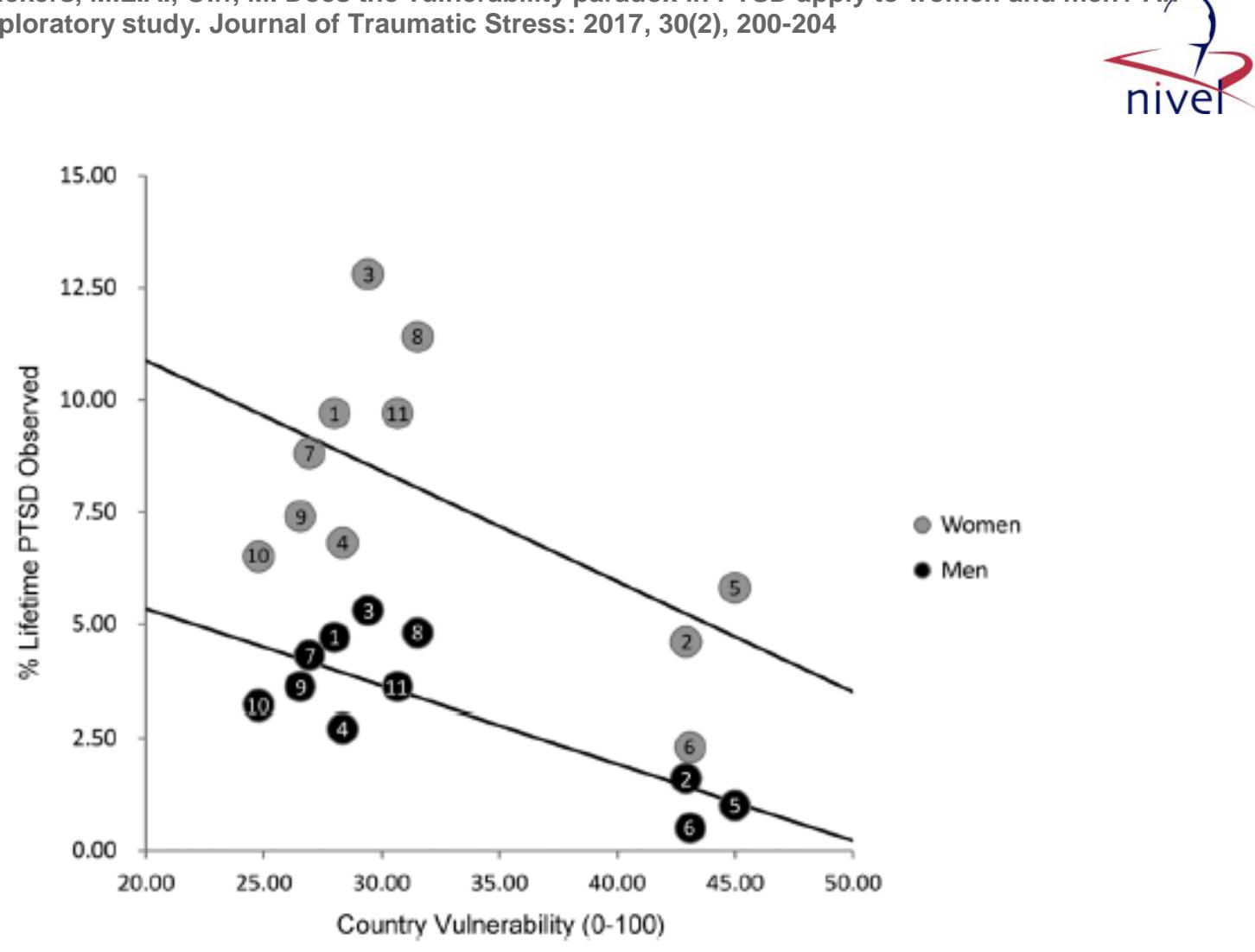

Figure 1. Vulnerability paradox in posttraumatic stress disorder in women and men. 1 = Australia, $2=$ Brazil, $3=$ Canada, $4=$ France, $5=$ Lebanon, $6=$ Mexico, $7=$ The Netherlands, $8=$ Portugal, $9=$ Sweden, $10=$ Switzerland, $11=$ United States. 